\title{
RISK OF HYPOTENSION IN PREGNANT LADIES UNDERGOING SPINAL ANESTHESIA INDUCED CESAREAN SECTION DELIVERIES.
}

\author{
DR. AMBER IRFAN, MBBS \\ Department of Obstetrics and Gynecology, \\ Sheikh Zayed Medical College, Rahim Yar Khan, Pakistan. \\ DR. SADAF IQBAL, MBBS \\ Department of Obstetrics and Gynecology, \\ Sheikh Zayed Medical College, Rahim Yar Khan, Pakistan.
}

DR. UROOJ IRFAN, MBBS

Department of Obstetrics and Gynecology,

Nishtar Medical University, Multan, Pakistan.

\begin{abstract}
Background; Cesarean section, one of most commonly performed surgical procedure, is associated with significant increase in maternal morbidities as well as mortalities. Objective: To determine frequency of hypotension in normotensive and preeclemptia patients undergoing spinal anaesthesia induced cesarean section. Material and Methods; Spinal anaesthesia was employed following standard technique after aspiration of free flow of CSF from needle in all four quadrants. After induction of spinal anaesthesia continuous monitoring of heart rate, oxygen situation and blood pressure was done immediately and at regular intervals of 5,10,15,20,.25 and 30 minutes to diagnose hypotension. Results; Mean gestational age of our study cases was noted to be 39.23 \pm 2.16 weeks and $101(69.2 \%)$ had gestational age more than 38 weeks. Mean age of our study cases was $27.49 \pm$ 2.93 years. Diabetes was presented in $19(13 \%)$ of our study cases. Status of blood pressure in pregnancy was also noted, $73(50 \%)$ were normotensive and $73(50 \%)$ were pre-eclamptic patients. Mean body mass index of our study cases was $26.23 \pm 1.92 \mathrm{~kg} / \mathrm{m}^{2}$ and obesity was present in $43(29.5 \%)$ of our study cases. Of these 146 study cases, $44(30.1 \%)$ had elective cesarean section and $102(69.9 \%)$ had emergency cesarean section. Hypotension was noted in $74(50.7 \%)$ of our study cases. Hypotension was $35.6 \%$ in normotensive cases while $65.8 \%$ among preeclamptic patients. Conclusion; Frequency of hypotension among women undergoing cesarean section with spinal anesthesia was high and hypotension was significantly more prevalent among women with the history of preeclampsia. Hypotension was significantly associated with age, residential status, monthly family income, diabetes, obesity and type of Cesarean section.
\end{abstract}

Keywords; cesarean section, hypotension, spinal anesthesia

DOI: $10.7176 / \mathrm{JMPB} / 61-06$

Publication date: November $30^{\text {th }} 2019$

\section{INTRODUCTION:}

Spinal anesthesia is a safe and effective alternative to general anesthesia when the surgical site is located on the lower extremities, perineum (eg, surgery on the genitalia or anus), or lower body wall ${ }^{1,2}$. The Greek philosopher "Dioscoride" first used the term Anaesthesia in the $1^{\text {st }}$ century AD to describe the Narcotic like effects of the plant "Mandragora" The present use of term to denote the sleep like state that makes painless surgery possible is 
credited to "Oliver Wendell Holmes" in 1846.In the united states use of the term "Anaesthesiology" to denote the practice or study of anaesthesia was first proposed in the $2^{\text {nd }}$ decade of the $20^{\text {th }}$ century to emphasize growing scientific basis of the specialty.

Anaesthesia is basically divided in to two categories i.e. General Anaesthesia \& Regional Anaesthesia (spinal anaesthesia, epidural anaesthesia, caudal anaesthesia, and Nerve blocks).

Spinal anaesthesia is a popular and widely used anaesthetic technique for lower abdominal, pelvic and lower limb surgery. It has proven to be convenient, economical and easily motivated technique which provides excellent anaesthesia and post operative analgesia.

Spinal anaesthesia causes hypotension due to blockade of sympathetic out flow. Neuroaxial blocks typically produce varibly decreases in blood pressure that may be accompanied by decrease in heart rate and cardiac contractility which can be prevented either by pre-loading the patients or by using vaso-pressor and ionotropic drugs $^{3}$. Allergy to local anesthetics may also be a contraindication, but true allergies are usually found with esterbased local anesthetics (eg, tetracaine), not the amide-based local anesthetics (eg, bupivacaine), so finding a suitable local anesthetic is not challenging ${ }^{4,5}$.

Like normotensive patients, however, preeclamptics may also experience hypotension after spinal anesthesia for cesarean delivery. The following variables were independently associated with the development of early hypotension : age, female sex, body mass index $>30 \mathrm{~kg} \mathrm{~m}-2$, history of preecleptia, diabetes mellitus, anaemia, baseline heart rate, systolic and diastolic blood pressure, pulse pressure, rate pressure product, vascular overload index, sensory level of blockade higher than or equal to $\mathrm{T}^{6}$. Bills et al suggest that circulating VEGF-A levels in preeclampsia are biologically active because of a loss of repression of VEGF-receptor 1 signaling by PlGF-1, and VEGF $_{165}$ b may be involved in the increased vascular permeability of preeclampsia ${ }^{7}$. Maternal hypotension is the most frequent complication of a spinal anaesthetic for caesarean section with an incidence approaching $100 \%$. The incidence of hypotension (systolic arterial blood pressure, SAP $<$ or $=100 \mathrm{~mm} \mathrm{Hg}$ ) was more frequent in the spinal group than in the epidural group (51\% versus $23 \%)$.

Systemic hypotension is the most common complication of spinal anaesthesia, with an incidence of $25-82 \%{ }^{8,9}$. The frequency of hypotension was lower in normotensive than preeclemptic group. Hypotension occurred in 9 out of 25 patients $(36 \%)$ in normotensive patient while 15 out of 25 patients $(60 \%)$ of preeclemptic group developed hypotension ${ }^{10}$.

\section{MATERIAL AND METHODS}

Pregnant ladies undergoing Cesarean section under spinal anaesthesia for normotensive and preeclamptic women aged 20 - 35 years having gestational age more than 37 weeks were included in our study. Patients having allergy to local anaesthetics, in shock, having co-morbid conditions like bleeding disorder, infection at site of injection, valvular heart diseases and spinal deformity were excluded from our study. Consecutive 146 pregnant ladies (both normotensive and pre-eclmaptic) meeting inclusion criteria undergoing spinal anesthesia induced cesarean section were included. This cohort study was conducted at Department of Obstetrics and Gynecology, Sheikh Zayed Medical College, Rahim Yar Khan. Two trolleys were prepared one containing equipment for spinal anesthesia and other will contain emergency drugs i.e. Atropine, Adrenaline, Ephedrine, hydro-cortisone and air way management kit. Baseline readings was taken for blood pressure \& pulse. Patients was pre-loaded with 10$20 \mathrm{ml}$ per Kg with colloids and crystalloids respectively. Spinal anaesthesia was employed following standard technique after aspiration of free flow of CSF from needle in all four quadrants. After induction of spinal anaesthesia continuous monitoring of heart rate, oxygen situation and blood pressure was done immediately and at regular intervals of 5,10,15,20,.25 and 30 minutes to diagnose hypotension. All the data was entered and analyzed using computer program SPSS version 20 to find out frequencies and percentages of categorical study variables like parity and hypotension, type of c. section, status of PIH (normotensive/pre-eclamptic), residential status BMI, and age groups. Descriptive statistics was used to calculate the mean and standard deviation for age and gestational age. Both groups will be compared by applying chi-square test at level of significance of 0.05 . 


\section{RESULTS;}

Our study comprised of a total of 146 patients meeting inclusion criteria of our study. Mean gestational age of our study cases was noted to be $39.23 \pm 2.16$ weeks and $101(69.2 \%)$ had gestational age more than 38 weeks. Mean age of our study cases was $27.49 \pm 2.93$ years (with minimum age of our study cases was 22 years while maximum age was 35 years). Our study results have indicated that majority of our study cases i.e. 120 (82.2\%) were aged up to 30 years. Of these 146 study cases, $57(39.0 \%)$ belonged to rural areas and $89(61.0 \%)$ belonged to urban areas. Monthly family income up to Rs. 35000 was noted in $51(34.9 \%)$ and $95(65.1 \%)$ had monthly family income more than Rs. 35000. Diabetes was presented in 19 (13\%) of our study cases. Status of blood pressure in pregnancy was also noted, $73(50 \%)$ were normotensive and $73(50 \%)$ were pre-eclamptic patients. Mean body mass index of our study cases was $26.23 \pm 1.92 \mathrm{~kg} / \mathrm{m}^{2}$ and obesity was present in $43(29.5 \%)$ of our study cases. Of these 146 study cases, $44(30.1 \%)$ had elective cesarean section and $102(69.9 \%)$ had emergency cesarean section. Hypotension was noted in $74(50.7 \%)$ of our study cases. Hypotension was $35.6 \%$ in normotensive cases while $65.8 \%$ among pre-eclamptic patients.

Table No. 1

Cross-tabulation of status of blood pressure in pregnancy with regards to hypotension.

$$
(\mathrm{n}=146)
$$

\begin{tabular}{|c|c|c|c|c|}
\hline \multirow[b]{2}{*}{ Status of BP } & \multicolumn{2}{|c|}{ "Hypotension } & \multirow[b]{2}{*}{$P$ - value } & \multirow[b]{2}{*}{$\begin{array}{c}\text { Relative } \\
\text { Risk }\end{array}$} \\
\hline & $\begin{array}{c}\text { Yes } \\
(\mathrm{n}=74)\end{array}$ & $\begin{array}{c}\text { No } \\
(n=72)\end{array}$ & & \\
\hline $\begin{array}{c}\text { Normotensive } \\
(\mathrm{n}=50)\end{array}$ & 26 & 47 & \multirow{3}{*}{0.000} & \multirow{3}{*}{0.542} \\
\hline $\begin{array}{c}\begin{array}{c}\text { Pre-eclamptic } \\
(\mathrm{n}=50)\end{array} \\
\end{array}$ & 48 & 25 & & \\
\hline Total & \multicolumn{2}{|c|}{146} & & \\
\hline
\end{tabular}

\section{DISCUSSION;}

Spinal anesthesia is considered to be safe as compared to general anaesthesia for caesarean section. Hypotension after spinal anaesthesia for caesarean delivery remains the major clinical problem. The hypotension is caused by an increase in venous capacitance and a reduction in systemic vascular resistance ${ }^{11-14}$.

Mean age of our study cases was $27.49 \pm 2.93$ years (with minimum age of our study cases was 22 years while maximum age was 35 years). Our study results have indicated that majority of our study cases i.e. 120 (82.2 $\%$ ) were aged up to 30 years. A study conducted by Hashim et al ${ }^{15}$ from Karachi reported $28.5 \pm 5$ years mean age of the women undergoing cesarean section which is close to our study results. Another study conducted by Sheikh et al ${ }^{16}$ from Karachi also reported $28 \pm 4.3$ years mean age of women undergoing cesarean section which is close to our study results. A study conducted by Saha et al ${ }^{17}$ from Bangladesh also reported similar results. A study conducted in USA by Boyle et al ${ }^{18}$ also reported 25 - 35 years of age was predominating among women undergoing cesarean section which is close to our study results.

Of these 146 study cases, 57 (39.0\%) belonged to rural areas and 89 (61.0\%) belonged to urban areas. Monthly family income up to Rs. 35000 was noted in 51 (34.9\%) and 95 (65.1\%) had monthly family income more than Rs. 35000. Diabetes was presented in $19(13 \%)$ of our study cases. Status of blood pressure in pregnancy was also noted, $73(50 \%)$ were normotensive and $73(50 \%)$ were pre-eclamptic patients. Mean body mass index of our study cases was $26.23 \pm 1.92 \mathrm{~kg} / \mathrm{m}^{2}$ and obesity was present in $43(29.5 \%)$ of our study cases. A study conducted in USA by Boyle et al ${ }^{18}$ also reported $11 \%$ diabetes which is in compliance with our study results. However Boyle et al ${ }^{18}$ high proportion of obesity which may be due to the high prevalence of obesity in United States. 
Of these 146 study cases, 44 (30.1\%) had elective cesarean section and $102(69.9 \%)$ had emergency cesarean section. A study conducted by Sheikh et al ${ }^{16}$ from Karachi also reported $80 \%$ emergency cesarean section deliveries which is in compliance with our study results. A study conducted by Saha et al ${ }^{17}$ from Bangladesh also reported $70 \%$ emergency cesarean section which is close to our study results. A study conducted in USA by Boyle et al ${ }^{18}$ also reported $82 \%$ emergency cesarean section among multiparous women which is in compliance with our study results.

Hypotension was noted in $74(50.7 \%)$ of our study cases. Hypotension was $35.6 \%$ in normotensive cases while $65.8 \%$ among pre-eclamptic patients. Hypotension occurred in 9 out of 25 patients $(36 \%)$ in normotensive patient while 15 out of 25 patients $(60 \%)$ of preeclemptic group developed hypotension ${ }^{10}$. These findings are close to our study results. A study conducted by Munir et al ${ }^{11}$ has also reported similar results.

\section{CONCLUSION;}

Frequency of hypotension among women undergoing cesarean section with spinal anesthesia was high and hypotension was significantly more prevalent among women with the history of pre-eclampsia. Hypotension was significantly associated with age, residential status, monthly family income, diabetes, obesity and type of Cesarean section.

\section{REFERENCES}

1. Braga Ade F, Frias JA, Braga FS, Pereira RI, Titotto SM. Spinal anesthesia for elective ceasarean section: use of different doses of hyperbaric bupivacaine associated with morphine and clonidine. Acta Cir Bras. 2013 jan;28(1):26-32.

2. Hoyle J, Yentis SM. Assessing the height of block for caesarean section over the past three decades: trends from the literature. Anaesthesia. 2015Apr;70(4):421-8.

3. Kleinman W, Mikhail M. Regional anaesthesia \& pain management. In: Morgan GE, Mikhail MS, Murray MJ. Clinical anaesthesiology. 4th ed. New York: Lange Medical Books/McGrawHill; 2006. p. 289-323.

4. Chattopadhyay A, Maitra S, Sen S, Bhattacharjee S, Layek A, Pal S, et al. A study to compare the analgesic efficacy of intrathecal bupivacaine alone with intrathecal bupivacaine midazolam combination in patients undergoing elective infraumbilical surgery. Anesthesiol Res Pract. 2013;2013:567134.

5. Hampl K, Steinfeldt T, Wulf H. Spinal anesthesia revisited: toxicity of new and old drugs and compounds.Curr Opin Anaesthesiol. 2014 Oct;27(5):549-55.

6. Singla D, Kathuria S, Singh S, Kaul TK, Gupta S, Mamta. Risk factors for development of early hypotension during spinal anaesthesia. J Anaesth Clin Pharmacol 2006; 22(4):387-93.

7. Bills V, Salmon A, Harper S, Overton TG, Neal CR, Jeffery B, et al. Impaired vascular permeability regulation caused by the $\operatorname{VEGF}(165)$ b splice variant in pre-eclampsia. BJOG. 2011 Sep;118(10):1253-61.

8. Niccolai P, Carles M, Lagha K, Raucoules-Aimé M. Prostate anaesthetic block with ropivacaine for urologic surgery. Eur J Anaesthesiol. 2005 Nov;22(11):864-9.

9. Yousaf M, Rabbani MW, Ahmad MS. Comparison of spinal anesthesia induced fall in blood pressure in normotensive and hypertensive patients. Pak J Med Health Sci. 2015;9(2):752-55.

10. Riaz A, Munzar Z. Preloading before spinal anesthesia for cesarean section. a comparison between colloid and crystalloid preload. Anesth Pain Intens Care.Jan - Jun 2006;10(1):9-12.

11. Kapustian V, Anteby EY, Gdalevich M, Shenhav S, Lavie O, Gemer O. Effect of closure versus nonclosure of peritoneum at cesarean section on adhesions: a prospective randomized study. Am J Obstet Gynecol. 2012;206:56.e1-4. 
12. Lyell DJ, Caughey AB, Hu E, Blumenfeld Y, El-Sayed YY, Daniels K. Rectus muscle and visceral peritoneum closure at cesarean delivery and intraabdominal adhesions. Am J Obstet Gynecol. 2012;206:515.e1-5.

13. Hasanin A, Mokhtar AM, Badawy AA, Fouad R. Post-spinal anesthesia hypotension during cesarean delivery, a review article. Egyp J Anes. 2017;33(2):189-93.

14. Munir S, Boota M, Kiyani F. Comparison of ephedrine versus fluid preload in prevention of hypotension after spinal anaesthesia for caesarean section. Pak Armed Forces Med J. 2013;63(1):http://www.pafmj.org/showdetails.php?id=673\&t=o

15. Hashim N, Nasir F, Razzaq A, Sonia Naqvi, Somroo N. Primary cesarean section in grandmultiparity. Rawal Med J. 2015;40(3):307-10.

16. Sheikh L, Tehseen S, Bhurgri H, Rizvi JH, Gowani SA, Kagazwala S. Reducing the rate of primary cesarean sections - an audit. J Pak Med Assoc. 2008;58:444-8.

17. Saha $L^{1}$, Chowdhury SB. Study on primary cesarean section. Mymensingh Med J. 2011 Apr;20(2):292-7.

18. Boyle $\mathrm{A}^{1}$, Reddy UM, Landy HJ, Huang CC, Driggers RW, Laughon SK. Primary cesarean delivery in the United States. Obstet Gynecol. 2013 Jul;122(1):33-40. 